\title{
Homocysteine in Retinal Vascular Occlusions
}

\author{
Dr. Tirupati Nath ${ }^{1}$, Dr. Rachit Agrawal ${ }^{2}$, Dr. Gunjan Prakash ${ }^{3}$
}

\begin{abstract}
Elevated plasma homocysteine (hcys) has been associated with a greater risk of heart disease and stroke. A number of studies have suggested that hcys may be a contributing factor to development of various ocular disease. Central retinal vein occlusion (CRVO) is one of the most common vision-threatening retinal vascular diseases, affecting primarily elderly patients. Several studies have demonstrated elevated hcys levels to be a potential risk factor in CRVO, but others failed to find such an association. Also, value of treating an elevated plasma hcys with folic acid for preventing further disease has not been proven. Although secondary prevention of coronary artery disease using this approach has been unsuccessful, trials on primary prevention of stroke and loss of cognitive function with folic acid supplementation appear to be successful. Further trial data are awaited. In this article we will review how systemic and local production of hcys might contribute to the pathogenesis of Retinal Vascular Occlusions.
\end{abstract}

Keywords: Homocysteine, Central Retinal Vein Occlusion, Folic acid

\section{Introduction}

Homocysteine (Hcys) is a sulfur-containing amino acid with a free thiol (sulfhydryl; SH) group, formed from methionine through S-adenosyl methionine in blood. ${ }^{1}$ Elevated plasma Hcys has been associated with a greater risk of heart disease ${ }^{2}$ and stroke. ${ }^{3}$ Ocular complications associated withhcys include primary open angle glaucoma, diabetic retinopathy, secondary glaucoma, optic atrophy, ARMD, CRVO, Cataract.

Blood levels of hyperhomocysteinemia (HHcy) are age and gender related. Plasma Hcy levels are higher in men than in women $^{4}$ and increase from $10.8 \mu \mathrm{mol} / \mathrm{L}$ at age $40-42$ years up to $12.4 \mu \mathrm{mol} / \mathrm{L}$ between $65-67$ years. ${ }^{5} \mathrm{HHcy}$ is classified as moderate $(15-30 \mu \mathrm{mol} / \mathrm{L})$, intermediate $(31-100 \mu \mathrm{mol} / \mathrm{L})$ or severe $(>100 \mu \mathrm{mol} / \mathrm{L}){ }^{6} \mathrm{HHcy}$ is observed in approximately $5 \%$ of the general ${ }^{7}$ population and has been associated with many disorders. ${ }^{8}$

Non-genetic factors for hyperhomocysteinemia include increasing age, various cardiovascular or cerebrovascular diseases, drugs (i.e. anti-epileptics), and lifestyle habits such as nutritional deficits, smoking, high coffee consumption, impaired renal function and poor vitamin B status (particularly folate status but also vitamin B6 and B12 status). In the elderly (age >75 years), hyperhomocysteinemia is generally associated with low folate status or renal impairment.

In this paper, we will explore the various aspects for how Hcys might contribute to the pathogenesis of Retinal Vascular Occlusions.

\section{Retinal Vascular Occlusions}

Central retinal vein occlusion (CRVO) is one of the most common vision-threatening retinal vascular diseases; it affects primarily elderly patients, resulting in macular edema, vitreous hemorrhage, and neovascular glaucoma. Several studies have demonstrated elevated Hcys levels to be a potential risk factor in CRVO, ${ }^{9-16}$ but others failed to find such an association. ${ }^{17-23}$ Thus, the role of Hcys in CRVO remains controversial.
There may be several explanations for these differences. First, age is an important confounding factor; there is evidence showing that Hcys increases with age. ${ }^{24}$ In studies that demonstrated an association between increased Hcys and CRVO, patients were significantly older than the control subjects. ${ }^{9,14,25,26}$ Second, sex (male or female) is an important confounding factor because hcys concentrations are greater in males than in females. ${ }^{27}$ In studies that demonstrated Hcys is an independent risk factor for CRVO, the constituent ratio of male patients was more than that of control subjects. ${ }^{11,12,15}$ Third, patient condition (fasting or non-fasting state) is an important confounding factor because hcys concentrations are greater in the non-fasting than in the fasting state. ${ }^{24}$ Two studies that reported an association, nonfasting blood samples were obtained from patients and control subjects in one study, and non-fasting blood samples were obtained from patients and fasting samples from control subjects in another study. ${ }^{10,25}$ Finally, in studies with a retrospective design, patients typically were recruited at variable intervals after onset of CRVO, and the mean time between CRVO occurrence and the determination of Hcys levels ranged from 1 to 69 months, which may have introduced variability in the measured Hcys concentrations..

It now is widely accepted in clinical practice that ischemic CRVO patients and nonischemic CRVO patients exhibit distinct clinical features, complications, courses, and prognoses, and, therefore, should be managed differently. Dong $\mathrm{N}$ Wang and $\mathrm{B}$ Chu L Xiao $\mathrm{L}^{23}$ showed that at the finally follow-up examination, three patients with nonischemic CRVO converted to ischemic CRVO. Interestingly, all three patients were defined as hyperhomocysteinemia. This suggests that hyperhomocysteinemia may be a predictor of nonischemic CRVO converted to ischemic CRVO, and of a poor prognosis.

\section{Conclusion}

The role of hcys in CRVO is complex. Observational studies have shown that CRVO in general population is associated with raised plasma hcys concentration. Evidence from controlled trials for any benefit from reduction of hcys is limited. Further research is required to study whether neuroprotection against elevated hcys (e.g. memantine) or 


\section{International Journal of Science and Research (IJSR) \\ ISSN (Online): 2319-7064}

Index Copernicus Value (2013): 6.14 | Impact Factor (2014): 5.611

lowering of hcys (e.g. fortification) will protect patients from further damage.

There is little data on the use of folic acid in primary prevention of ocular diseases but there is a suggestion from epidemiological studies that a high folate intake and also vitamin B12 supplements may be protective against the development of nuclear cataract. ${ }^{23}$ The ongoing Folic Acid and Carotid Intimal Thickness (FACIT) trial has reported significant improvements in cognitive function in subjects aged 50-70 years with baseline elevation of plasma hcys concentrations $^{29}$ and a useful meta-analysis of eight randomized trials of folic acid supplementation showed reduction in the risk of stroke by $18 \%$.

In the meantime, while the outcomes of further large, randomized trials are awaited, we would recommend measurement of fasting plasma homocysteine in patients with CRVO. The use of folic acid supplementation if hyperhomocystinaemia is identified in these situations is not based on firm evidence but the results from stroke prevention are encouraging.

\section{References}

[1] CastroR, RiveraI, BlomHJ, JakobsC, de AlmeidaIT. Homocysteine metabolism, hyperhomocysteinemia and vascular disease: an overview. J Inherit Metab Dis. 2006;29:3- 20.

[2] Perła-KajánJ, TwardowskiT, JakubowskiH. Mechanisms of homocysteine toxicity in humans. Amino Acids. 2007;32(4)561-72.

[3] LominadzeD, RobertsAM, TyagiN, MoshalKS, TyagiSC. Homocysteine causes cerebrovascular leakage in mice. Am J Physiol Heart Circ Physiol. 2006;290(3)H1206-13.

[4] Metz J, Bell AH, Flicker L, et al. The significance of subnormal serum vitamin B12 concen- tration in older people: a case control study. J Am Geriatr Soc. 1996;44:1355-61.

[5] Nurk E, Tell GS, Nygard O, et al. Plasma total homocysteine is influenced by prandial status in humans: the HordalandHomocysteine Study. J Nutr. 2001;131:1214-6.

[6] Weiss N, Keller C, Hoffmann U, et al. Endothelial dysfunction and atherothrombosis in mild hyperhomocysteinemia. Vasc Med. 2002;7:227-39.

[7] Brustolin S, Giugliani R, Félix T.M. Genetics of homocysteine metabolism and associated disorders Brazilian Journal of Medical and Biological Research. 2010;43: 1-7.

[8] Rosenberg EA, Sperazza LC. The visually impaired patient. AmFam Physician. 2008;77:1431-6.

[9] Vine AK. Hyperhomocysteinemia: a risk factor for central retinal vein occlusion. Am J Ophthalmol.2000;129:640-4.

[10] Abu El-Asrar AM, Abdel Gader AG, Al-Amro SA, AlAttas OS. Hyperhomocysteinemia and retinal vascular occlusive disease. Eur J Ophthalmol . 2002;12:495500.

[11] Ferrazzi P Di Micco P Quaglia I Homocysteine, MTHFR C677T gene polymorphism, folic acid and vitamin B 12 in patients with retinal vein occlusion. ThrombJ . 2005;3:13.

[12] Yildirim C Yaylali V Tatlipinar S Kaptano. lu B Akpinar S. Hyperhomocysteinemia: a risk factor for retinal vein occlusion. Ophthalmologica 2004;218:102-6.

[13] Weger M Stanger O Deutschmann H Hyperhomocyst(e)inemia and MTHFR C677T genotypes in patients with central retinal vein occlusion. Graefes Arch ClinExpOphthalmol 2002;240:286-90.

[14] Martin SC Rauz S Marr JE Martin N Jones AF Dodson PM. Plasma total homocysteine and retinal vascular disease. Eye . 2000;14:590-3.

[15] Moghimi S Najmi Z Faghihi H Karkhaneh R Farahvash MS Maghsoudipour M. Hyperhomocysteinemia and central retinal vein occlusion in Iranian population. IntOphthalmol . 2008;28:23-8.

[16] McGimpsey SJ Woodside JV Cardwell C Cahill M Chakravarthy U. Homocysteine, methylenetetrahydrofolatereductase C677T polymorphism, and risk of retinal vein occlusion: a meta-analysis. Ophthalmology . 2009;116:1778-87.

[17] Boyd S Owens D Gin T Plasma homocysteine, methylene tetrahydrofolatereductase C677T and factor II G20210A polymorphisms, factor VIII, and VWF in central retinal vein occlusion. $\mathrm{Br} \mathrm{J}$ Ophthalmol . 2001;85:1313-5.

[18] Pianka P Almog Y Man O Goldstein M Sela BA Loewenstein A. Hyperhomocystinemia in patients with nonarteritic anterior ischemic optic neuropathy, central retinal artery occlusion, and central retinal vein occlusion. Ophthalmology . 2000;107:1588-92.

[19] Larsson J Hultberg B Hillarp A. Hyperhomocysteinemia and the MTHFR C677T mutation in central retinal vein occlusion. ActaOphthalmolScand . 2000;78:340-3.

[20] Pinna A Carru C Zinellu A Dore S Deiana L Carta F. Plasma homocysteine and cysteine levels in retinal vein occlusion. Invest Ophthalmol Vis Sci . 2006;47:406771.

[21] McGimpsey SJ Woodside JV Bamford L Retinal vein occlusion, homocysteine, and methylene tetrahydrofolatereductase genotype. Invest Ophthalmol Vis Sci . 2005;46:4712-6.

[22] Di Crecchio L Parodi MB Sanguinetti G Iacono $P$ Ravalico G. Hyperhomocysteinemia and the methylenetetrahydrofolatereductase $677 \mathrm{C}-\mathrm{T}$ mutation in patients under 50 years of age affected by central retinal vein occlusion. Ophthalmology . 2004;111:940-5.

[23] Dong N Wang B Chu L Xiao L. Plasma homocysteine concentrations in the acute phase after central retinal vein occlusion in a Chinese population. Curr Eye Res . 2013;38:1153-8.

[24] Refsum H Smith AD Ueland PM Facts and recommendations about total homocysteine determinations: an expert opinion. ClinChem . 2004;50:3-32.

[25] Vine AK. Hyperhomocysteinemia: a new risk factor for central retinal vein occlusion. Trans AmOphthalmolSoc.2000;98:493-503. 


\section{International Journal of Science and Research (IJSR) \\ ISSN (Online): 2319-7064}

Index Copernicus Value (2013): 6.14 | Impact Factor (2014): 5.611

[26] Marcucci R Bertini L Giusti B Thrombophilic risk factors in patients with central retinal vein occlusion. ThrombHaemost . 2001;86:772-6.

[27] Marouf R Zubaid M Mojiminiyi OA Determinants of plasma homocysteine in relation to hematological and biochemical variables in patients with acute myocardial infarction. South Med J . 2006;99:811-6.

[28] Kuzniarz M, Mitchell P, Cumming RG, Flood VM. Use of vitamin supplements and cataract: the blue mountain eye study. Am J Ophthalmol 2001;132:19-26.

[29] Durga J, van Boxtel MP, Schouten EG, Kok FJ, Jolles J, Katan MB et al. Effect of 3-year folic acid supplementation on cognitive function in older adults in the FACIT trial: a randomised, double blind, controlled trial. Lancet 2007;369:208-16. 